\title{
Sublingual immunotherapy: time to reconsider compliance and adherence
}

\author{
Peter Friedrich Eberle \\ From 3rd WAO International Scientific Conference (WISC) 2014 \\ Rio de Janeiro, Brazil. 6-9 December 2014
}

\section{Background}

Quality of life (QoL) in patients treated with sublingualimmunotherapy (SLIT) is assessed and compared to QoL in general population aiming to challenge the thesis that non-perception of efficacy by the patient is one of the main causes for poor adherence in SLIT.

\section{Methods}

We conducted a non-interventional, cross-sectional and retrospective quality-of -life- survey including 201 patients treated with SLIT at one pediatric practice in Germany. Clinical or demographical characteristics of the examined patients were not interrogated. Patients' compliance was calculated based on the duration of active treatment participation. Quality of life was assessed with the generic SF-12 health survey in German language. The items interrogated within the SF-12 health survey are weighted, added up and transformed to a physical component score (PCS) and a mental component score (MCS). The component scores range from 0 to 100 , the higher the score the better QoL is perceived.

\section{Results}

Patients' compliance with SLIT between 2009 and 2014 resulted in a continuation of the treatment by $76-82 \%$ in the second and by $60-70 \%$ in the third year of therapy. The interrogated patients who have been treated with SLIT show a PCS-12 of 49,3 $( \pm 7,0)$ and a MCS-12 of $52,6( \pm 7,2)$. A different study examining the health status of the German general population $(\mathrm{n}=2453)$ results in a PCS-12 of $49,6( \pm 8,7)$ and a MCS-12 of 52,3 $( \pm 8,0)[1]$. While patients suffering from perennial or seasonal allergic rhinitis and asthma have significant lower QoL than their control group [2].These observations indicate that patients treated with SLIT have a

\footnotetext{
Private office, Kassel, Hesse, Zipcode 34121, Wilhelmshöher Allee 109,
} Germany

\section{and take full advantage of:}

- Convenient online submission

- Thorough peer review

- No space constraints or color figure charges

- Immediate publication on acceptance

- Inclusion in PubMed, CAS, Scopus and Google Scholar

- Research which is freely available for redistribution 